\title{
Fracture rate and back pain during and after discontinuation of teriparatide: 36-month data from the European Forsteo Observational Study (EFOS)
}

\author{
A. Fahrleitner-Pammer • B. L. Langdahl • F. Marin • \\ F. Jakob • D. Karras • A. Barrett • Ö. Ljunggren • \\ J. B. Walsh • G. Rajzbaum • C. Barker • W. F. Lems
}

Received: 16 July 2010 / Accepted: 27 October 2010 / Published online: 27 November 2010

(C) The Author(s) 2010. This article is published with open access at Springerlink.com.

\begin{abstract}
Summary In this observational study in postmenopausal women with severe osteoporosis, the incidence of fractures was decreased during 18 months of teriparatide treatment with no evidence of further change in the subsequent 18month post-teriparatide period when most patients took other osteoporosis medications. Fracture reduction was accompanied by reductions in back pain.

Introduction To describe fracture outcomes and back pain in postmenopausal women with severe osteoporosis during 18 months of teriparatide treatment and 18 months postteriparatide in normal clinical practice.

Methods The European Forsteo Observational Study (EFOS) was a prospective, multinational, observational study. Data on incident clinical fractures and back pain
\end{abstract}

Electronic supplementary material The online version of this article (doi:10.1007/s00198-010-1498-5) contains supplementary material,

which is available to authorized users.

\footnotetext{
A. Fahrleitner-Pammer

Medical University,

Graz, Austria

B. L. Langdahl

Aarhus University Hospital,

Aarhus, Denmark

F. Marin $\cdot$ A. Barrett $\cdot$ C. Barker

Lilly Research Centre,

Windlesham, UK

F. Jakob

Julius-Maximilians University,

Würzburg, Germany

D. Karras

Veterans Administration Hospital,

Athens, Greece
}

(100 mm Visual Analogue Scale [VAS] and questionnaire) were collected. Fracture data were summarised in 6-month intervals and analysed using logistic regression with repeated measures. Changes from baseline in back pain VAS were analysed using a repeated measures model.

Results A total of 208 (13.2\%) of 1,576 patients sustained 258 fractures during 36 months of follow-up: $34 \%$ were clinical vertebral fractures and $66 \%$ non-vertebral fractures. The adjusted odds of fracture were reduced during teriparatide treatment and there was no evidence of further change in the 18-month post-teriparatide period, during which $63.3 \%$ patients took bisphosphonates. A $74 \%$ decrease in the adjusted odds of fracture in the 30- to $<36$-month period compared with the first 6 -month period was observed $(p<$ $0.001)$. Back pain decreased during teriparatide treatment

Ö. Ljunggren

Uppsala University Hospital,

Uppsala, Sweden

J. B. Walsh

Trinity College,

Dublin, Ireland

G. Rajzbaum

Hospital St Joseph,

Paris, France

W. F. Lems $(\bowtie)$

Department of Rheumatology 3a 61,

VU University Medical Centre,

Postbox 7057, 1007 MB, Amsterdam, The Netherlands

e-mail: wf.lems@vumc.nl 
and this decrease was sustained after teriparatide discontinuation. Adjusted mean back pain VAS decreased by $26.3 \mathrm{~mm}$ after 36 months $(p<0.001)$ from baseline mean of $57.8 \mathrm{~mm}$.

Conclusions In a real-life clinical setting, the risk of fracture decreased during teriparatide treatment, with no evidence of further change after teriparatide was discontinued. The changes in back pain seen during treatment were maintained for at least 18 months after teriparatide discontinuation. These results should be interpreted in the context of the design of an observational study.

Keywords Back pain · Fracture - Osteoporosis · Teriparatide

\section{Introduction}

Postmenopausal women with osteoporosis have an increased risk of fracture and its associated complications, such as back pain and disability/functional impairment, which can lead to a reduced health-related quality of life (HRQoL) [1-9]. Clinical vertebral and hip fractures are also associated with increased mortality [10, 11]. Treatment aims to reduce the risk, incidence and burden of osteoporosis-related fractures.

Teriparatide, a recombinant human N-terminal fragment of parathyroid hormone (rhPTH 1-34), is a bone anabolic agent that increases bone mass and strength. In a placebocontrolled trial, daily teriparatide treatment for 19 months reduced the risk of vertebral and non-vertebral fractures in postmenopausal women with severe osteoporosis [12]. Teriparatide is approved for a limited treatment duration and is typically used as a second-line treatment option in postmenopausal women with severe osteoporosis. Thus, many patients receiving teriparatide have previously been treated with antiresorptive therapies and require further osteoporosis medication after teriparatide is discontinued. However, there is limited published data on the use of teriparatide as a sequential treatment for osteoporosis, particularly in a real-life clinical practice setting.

Most previous studies reporting the effects of teriparatide in postmenopausal women have been controlled clinical trials with strict inclusion criteria and highly selected patient populations; patients with co-morbidities, such as rheumatoid arthritis, and those taking concomitant medications are often excluded. It has been estimated that about $80 \%$ of patients receiving treatment for osteoporosis would not be eligible for inclusion in a randomised controlled trial [13]. Since observational studies have few exclusion criteria, they can investigate treatment effects in a broader range of patients in the routine care setting, and can provide valuable supporting information that is applicable in clinical practice [14]. No previous observational studies have examined the effectiveness and safety of teriparatide during and after treatment.

The European Forsteo Observational Study (EFOS) was a 36-month, prospective, observational study designed to evaluate fracture outcomes, back pain and HRQoL in postmenopausal women with severe osteoporosis treated with teriparatide in the outpatient setting for a maximum of 18 months, followed by a post-teriparatide treatment period of a further 18 months. We report here the main study analyses for the total study cohort followed up for 36 months, i.e., the incidence of clinical vertebral and non-vertebral fractures and changes in back pain, both during teriparatide treatment and in the 18 months after teriparatide discontinuation. The changes in fracture risk, back pain and HRQoL during 18 months of teriparatide treatment in EFOS have been previously reported [15].

\section{Methods}

Study design and patients

The study design and characteristics of the EFOS patient population have been described previously [16]. Briefly, 1,649 postmenopausal women with a diagnosis of osteoporosis who were about to initiate teriparatide treatment were enrolled in eight European countries (Austria, Denmark, France, Germany, Greece, Ireland, the Netherlands, and Sweden). Patients were followed for the duration of their teriparatide treatment, which they could discontinue at any time, and were asked to return for two additional visits after they discontinued teriparatide. Patients were not included if they were currently being treated with an investigational drug or procedure, or had any contraindications as described in the teriparatide label. Because this was an observational study, there were no further restrictions for the selection of patients. Patients gave written informed consent prior to enrolment and were able to withdraw without consequence at any time. The study was approved by local ethics committees or review boards, depending on local requirements.

\section{Data collection}

At the baseline visit, patient demographic characteristics, risk factors for osteoporosis and falls, osteoporosis therapies and disease status were recorded [16]. The women attended visits at baseline and at approximately 3, 6, 12 and 18 months after teriparatide initiation, and at 6 and 18 months after discontinuing teriparatide treatment.

Incident clinical vertebral and non-vertebral fractures, the primary study endpoint, were diagnosed and confirmed by review of the original X-rays and/or the radiology or 
surgical reports at the investigational site. A new or worsened vertebral fracture was defined from the presence of a confirmed radiographic vertebral fracture associated with signs and/or symptoms, such as acute or severe back pain, suggestive of a vertebral fracture [17].

Back pain was self-assessed by patients at each visit using a back pain questionnaire detailing frequency and severity in the past month, limitations of activities and days in bed due to back pain [15]. Patients also rated their back pain severity using a horizontal $100 \mathrm{~mm}$ visual analogue scale (VAS), ranging from $0 \mathrm{~mm}$ (no back pain) to $100 \mathrm{~mm}$ (worst possible back pain). This type of VAS is reliable and reproducible for the measurement of pain [18].

Spontaneously reported adverse events were collected throughout the study.

\section{Statistical analysis}

Data were analysed for the total study cohort, which included all patients with a baseline visit and at least one follow-up visit. In addition, the post-teriparatide cohort included those patients who discontinued teriparatide and had at least one post-teriparatide follow-up visit.

Results for the active treatment period have already been published [15].

Descriptive statistics were used to describe the study population.

The number of fractures occurring in patients was summarised in 6-month intervals. A logistic regression with repeated measures was used to assess the change in number of patients with one or more fractures over time $[19,20]$. In contrast to survival analysis, where the hazard of the first fracture is presented, logistic regression is an analysis of the odds of fracture (e.g., ratio of patients who fracture versus patients who do not fracture). Patients were included in the model at all observed intervals, regardless of whether or not they fractured during a previous interval. The repeated observations of each patient were assumed to be related but no further assumptions were made about the relationship. Unadjusted and adjusted models were performed including age, prior bisphosphonate use and a history of fracture in the last 12 months before starting teriparatide. Contrasts were made between the odds of fracture in the first 6 months of treatment ( 0 to $<6$ months) and each subsequent 6 -month period. Fracture modelling was repeated for all vertebral, all non-vertebral and main non-vertebral (forearm/wrist, hip, humerus, leg and ribs) fractures.

Back pain VAS changes from baseline were analysed using a mixed model for repeated measures (MMRM) adjusting for back pain VAS at baseline, number of previous fractures, age, diagnosis of rheumatoid arthritis, duration of prior bisphosphonate therapy, and a history of fracture in the 12 months before entering the study. The $p$ values represent the unique influence of the corresponding factor after adjustment for all other factors in the model. The number of patients reporting an improvement or worsening in the severity, frequency, limitation of activities and number of days in bed ( $\leq 2$ days: no change) due to back pain was analysed using the sign test.

\section{Results}

Patient disposition and characteristics

Figure 1 summarises the patient flow through the study and the number of patients with observations at each visit for the total study cohort and the post-teriparatide cohort. Overall, 1,581 patients were analysed at baseline and returned for at least one post-baseline visit; this constitutes the total study cohort. As this was an observational study with data collection occurring within the normal course of clinical care, some patients missed subsequent targeted data collection visits (as detailed in Fig. 1) but returned for a later visit. Moreover, at each time point, no further data were available for some patients (i.e., these patients discontinued or were lost to follow-up). The baseline characteristics of the total study cohort are summarised in Table 1.

\section{Teriparatide treatment}

The median duration of teriparatide treatment was 541 days (Q1, Q3: 432, 552 days) for the total study cohort and 545 days (Q1, Q3: 533, 553 days) for the subset of patients in the post-teriparatide cohort $(n=909)$. Persistence with teriparatide treatment is shown in Fig. S1.

The main reasons for discontinuation of teriparatide in the total study cohort were treatment completed ( $n=871 ; 77.9 \%)$, patient decision $(n=120 ; 10.7 \%)$, adverse event $(n=85$; $7.6 \%)$, physician decision $(n=30 ; 2.7 \%)$, death $(n=12$; $1.1 \%)$ and non-compliance $(n=5 ; 0.4 \%)$.

Osteoporosis medication after teriparatide

Of the 907 patients with data available on osteoporosis medication taken after teriparatide was discontinued, 70.7\% took an antiresorptive drug, mainly bisphosphonates (63.3\%). The drugs most commonly taken at some point after stopping teriparatide were alendronate $(32.1 \%)$, risedronate $(20.0 \%)$, raloxifene $(6.1 \%)$ and calcitonin (4.2\%). Most patients also took calcium (84.5\%) and vitamin D (86.2\%). Supplementary data available for 676 patients showed that $5.0 \%$ received strontium ranelate after stopping teriparatide and two patients received full-length parathyroid hormone (rhPTH1-84). 


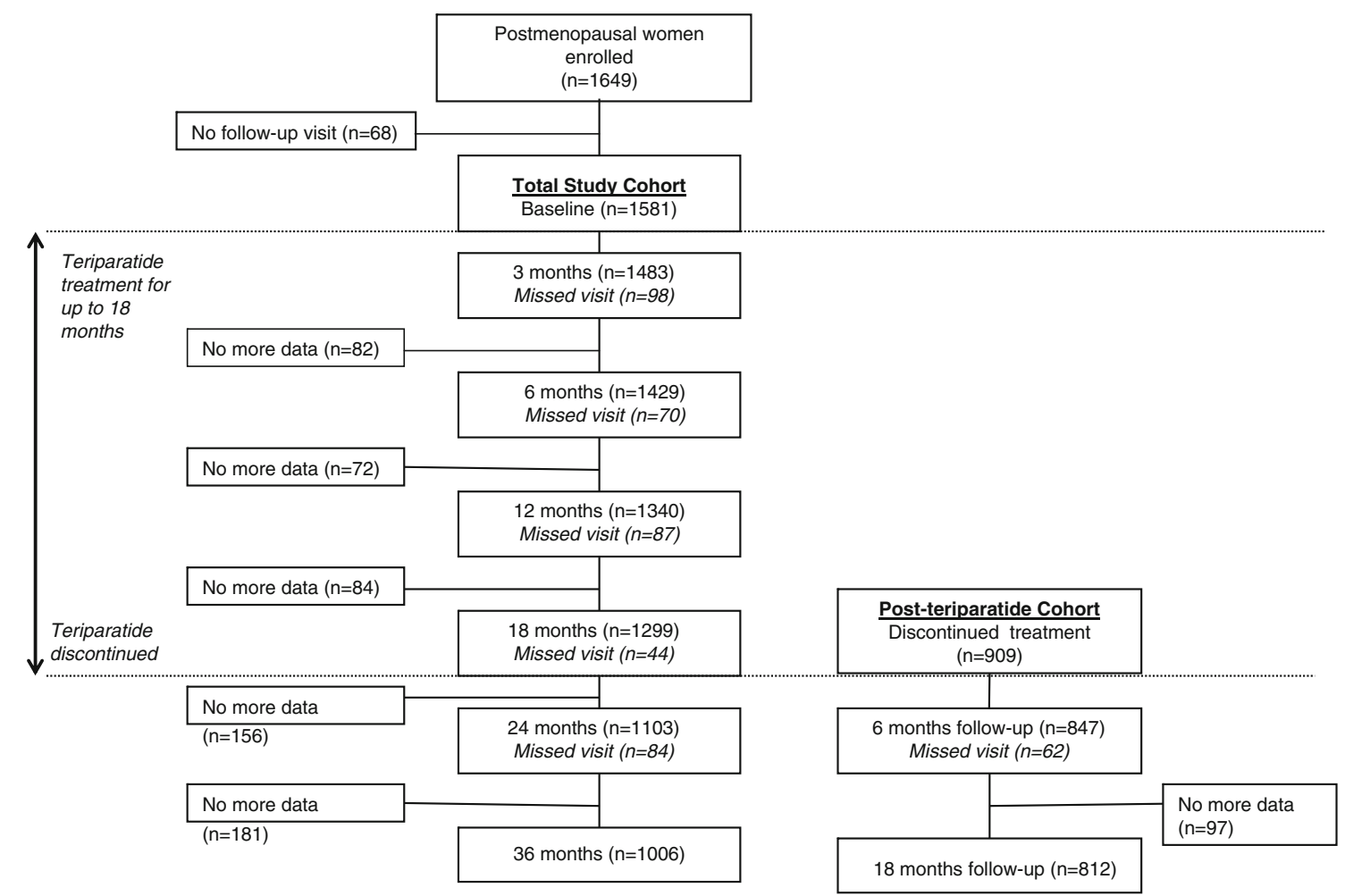

Total study cohort: all patients with a baseline visit and at least one post-baseline visit

Post-teriparatide cohort: patients who discontinued teriparatide (regardless of time) and had at least one post-treatment follow-up visit

Fig. 1 Study flow and disposition of patients in the total study cohort and post-teriparatide cohort

\section{Fractures}

Table 2 shows the incidence of fractures during and after teriparatide treatment for the total study cohort. Of these 1,581 women, $208(13.2 \%)$ sustained a total of 258 clinical fractures during the 36-month follow-up. Of the 208 women with fractures, 170 sustained a single fracture and 38 sustained two or more fractures. Of the 258 fractures, 87 (33.7\%) were clinical vertebral fractures and $171(66.3 \%)$ were non-vertebral fractures; $129(50.0 \%)$ of all fractures were main non-vertebral fractures at the forearm/wrist $(n=$ $41)$, hip $(n=27)$, humerus $(n=21)$, leg $(n=21)$ and ribs $(n=$ $19)$. The number of fractures $/ 10,000$ patient years was highest in the first 6 months and decreased in each subsequent 6-month interval (Table 2).

Figure 2 presents the adjusted odds of fracture (95\% confidence interval [CI]) by fracture type for each 6-month interval in the total study cohort (adjusted by age, prior bisphosphonate use and history of fracture in the 12 months before starting teriparatide). For all fractures and for vertebral fractures, there was a significant reduction in the adjusted odds of fracture at 12 to $<18$ months of teriparatide treatment and during the post-teriparatide intervals compared with the first 6 months of teriparatide treatment. For all fractures, there was a $74 \%$ decrease in the adjusted odds of fracture in the 30 - to $<36$-month period compared with 0 to $<6$ months $(p<0.001)$. The odds of having a non-vertebral fracture were significantly lower during the 24 - to $<30$-month interval (OR $0.40,95 \%$ CI 0.21 to 0.75 ) and 30 - to $<36$-month interval (OR 0.41 , 95\% CI 0.22 to 0.76 ), compared with the first 6 months of teriparatide treatment. Similar results were observed for the main non-vertebral fractures.

After adjusting for the other relevant risk factors, patients who had a fracture in the 12 months before baseline were more likely to fracture during the study than patients without a fracture in the 12 months before baseline (119 [15.6\%] of 761 patients and 89 [10.9\%] of 815 patients, respectively, experienced a fracture during the study): adjusted OR 1.39 (95\% CI 1.05-1.83). In addition, patients who used bisphosphonates prior to teriparatide were more likely to fracture during the study than those without prior bisphosphonate use (169 [14.6\%] of 1,161 patients and 39 [9.3\%] of 420 patients, respectively, experienced a fracture during the study): adjusted OR 1.64 (95\% CI 1.16-2.33) for main non-vertebral fractures (also significant for all fractures and all non-vertebral fractures).

In a sensitivity analysis of only those patients who completed the 36-month follow-up ( $n=991,62.7 \%$ of total study cohort), which contained $91 \%$ of the total fractures and $73.1 \%$ of the total women with an incident clinical fracture during the 36-month follow-up, the results were 
Table 1 Baseline characteristics of total study cohort $(n=1,581)$
Characteristic

Total study cohort

Caucasian, $\%$

99.2

Age, years

$71.0(8.4)$

Years since menopause

$24.8(9.0)$

Early menopause ( $<40$ years of age), $\%$

8.9

Surgical menopause, $\%$

18.7

Nulliparous, $\%$

13.1

BMI, $\mathrm{kg} / \mathrm{m}^{2}$

$25.1(4.3)$

Current smoker, $\%$

13.0

Hip fracture in mother, $\%$

20.8

Number of previous fractures after 40 years of age

$2.9(2.0)$

Time since most recent fracture, years ${ }^{\text {a }}$

$2.1(3.4)$

48.4

At least one fracture in 12 months prior to study entry,\%

92.3

Prior osteoporosis medication, $\%$

73.4

Prior bisphosphonate use, $\%$

32.5

Co-morbidities, $\%$

11.9

Rheumatoid arthritis

8.7

Chronic obstructive pulmonary disease

5.5

Diabetes mellitus

63.8

Concomitant medications, $\%{ }^{\mathrm{b}}$

37.2

Antihypertensives

14.8

Glucocorticoids

13.3

Thyroid hormone

$-3.26(1.16)$

Lumbar spine BMD, T score

$-2.61(1.05)$

Total hip BMD, T score

${ }^{\mathrm{b}}$ The three most frequently used are listed

change in back pain VAS from baseline over time. The

similar to those for the total study cohort given in Table 2 (data not shown). decrease in pain seen during the 18 months of teriparatide treatment was maintained during the 18 months after

Back pain teriparatide was discontinued. Of the variables included in the MMRM, three had a significant effect on the change in The mean (SD) back pain VAS at baseline was 57.8 (26.6) for the total study cohort. Figure 3 shows the adjusted mean back pain VAS: each additional $5 \mathrm{~mm}$ in baseline VAS was associated with a greater improvement in back pain of

Table 2 Incident clinical fractures during teriparatide treatment ( 0 to $<18$ months) and after discontinuation of teriparatide $(18$ to $<36$ months $)$ for the total study cohort

\begin{tabular}{|c|c|c|c|c|c|c|}
\hline $\begin{array}{l}\text { Time interval } \\
\text { (months) }\end{array}$ & $\begin{array}{l}N \text { (missing/ } \\
\text { unknown) }\end{array}$ & $\begin{array}{l}\text { No. of fractures } \\
\text { per } 10,000 \text { patient years }\end{array}$ & $\begin{array}{l}\text { Total number } \\
\text { of fractures }\end{array}$ & $\begin{array}{l}\text { Patients with } \geq 1 \\
\text { fracture, } n(\%)^{\mathrm{a}}\end{array}$ & $\begin{array}{l}\text { Odds ratio } \\
(95 \% \mathrm{CI})\end{array}$ & $p$ value \\
\hline 0 to $<6$ & $1,581(5)$ & 1,119 & 86 & $76(4.8)$ & & \\
\hline 6 to $<12$ & $1,475(2)$ & 815 & 58 & $51(3.5)$ & $0.706(0.497-1.003)$ & 0.052 \\
\hline 12 to $<18$ & $1,371(1)$ & 645 & 43 & $41(3.0)$ & $0.609(0.413-0.899)$ & 0.013 \\
\hline 18 to $<24$ & $1,271(2)$ & 606 & 36 & $34(2.7)$ & $0.547(0.361-0.828)$ & 0.004 \\
\hline 24 to $<30$ & $1,109(4)$ & 387 & 20 & $18(1.6)$ & $0.331(0.197-0.559)$ & $<0.001$ \\
\hline 30 to $<36$ & $991(0)$ & 327 & 15 & $13(1.3)$ & $0.265(0.147-0.478)$ & $<0.001$ \\
\hline Total & $1,581(5)$ & & 258 & $208(13.2)$ & & \\
\hline
\end{tabular}

$N=$ number of patients included in the observation

${ }^{a}$ As some patients experienced a fracture in more than one time interval, the total was not the sum of patients with a fracture in each interval

${ }^{\mathrm{b}}$ Adjusted model by age, prior bisphosphonate use and a history of fracture in the last 12 months before starting teriparatide

${ }^{\mathrm{c}}$ Compared with 0 to $<6$ months interval 


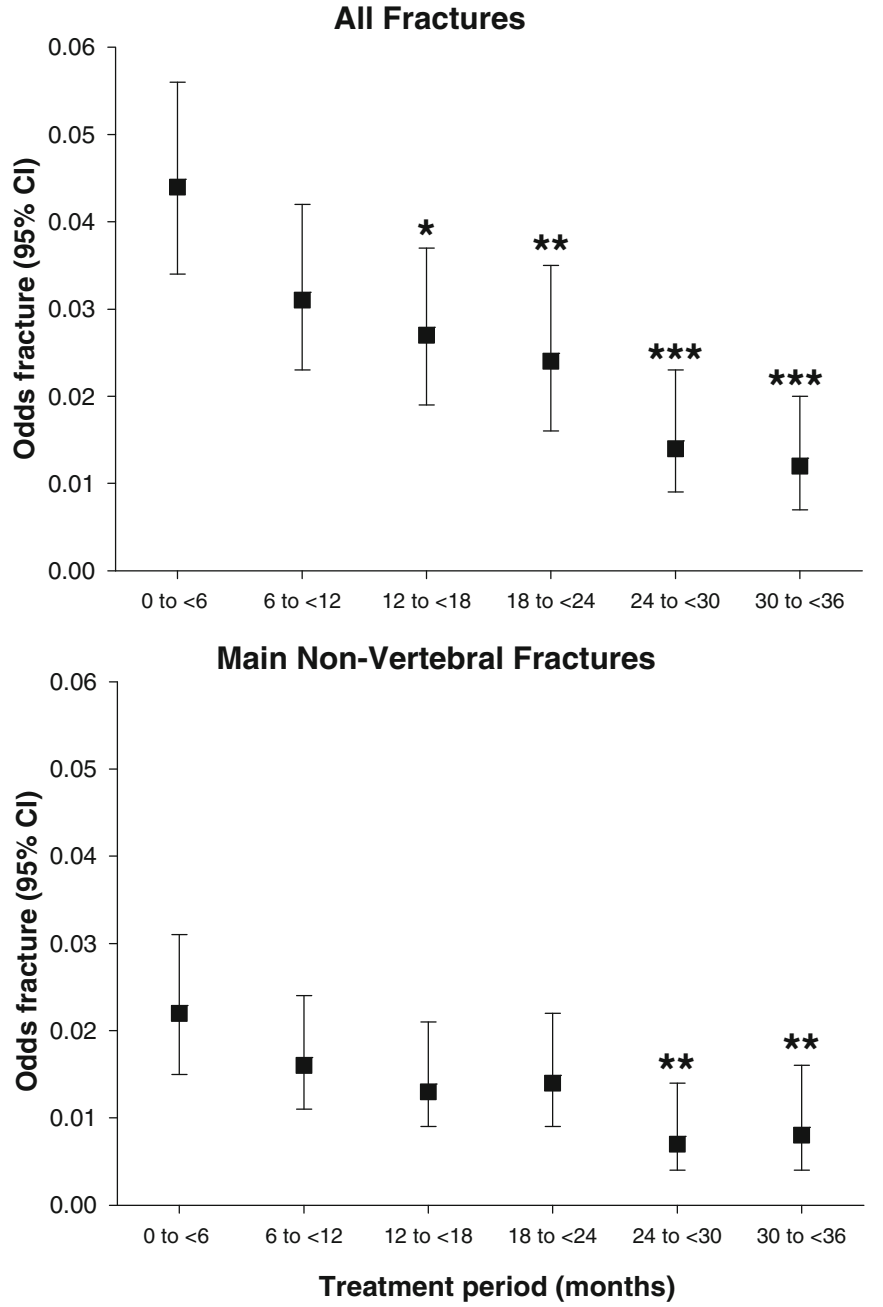

Fig. 2 Adjusted odds of fracture $(95 \%$ CI) by fracture type (all fractures pooled, clinical vertebral, non-vertebral and main nonvertebral) in each 6-month interval for the total study cohort. Note: ${ }^{*} p \leq 0.05 ; * * p \leq 0.01 ; * * * p \leq 0.001$ versus 0 to $<6$ months; model: log $($ OddsofFracture $)=6$ month interval + age + prior bisphosphonate use

$-2.89 \mathrm{~mm}(95 \% \mathrm{CI}-3.07$ to $-2.71 ; p<0.001)$; a fracture in the past 12 months before treatment start was associated with a greater improvement in back pain of $-2.49 \mathrm{~mm}(95 \%$ CI -4.43 to $-0.56 ; p=0.012$ ) versus no fracture in the past 12 months; whereas each additional historical fracture was associated with less improvement in back pain of $1.10 \mathrm{~mm}$ (95\% CI 0.61 to $1.58 ; p<0.001)$.

The results from the back pain questionnaire for the total study cohort are summarised in Table 3. Both the frequency and severity of back pain decreased during teriparatide treatment and this was maintained after teriparatide was discontinued. At every post-baseline visit, there were significantly more patients who reported a decrease compared with an increase in the frequency of back pain relative to baseline (sign test, $p<0.001$ ). The same was true for the severity of back pain (sign test, $p<0.001$ ). The limitations on activities and days in bed due to back pain decreased during
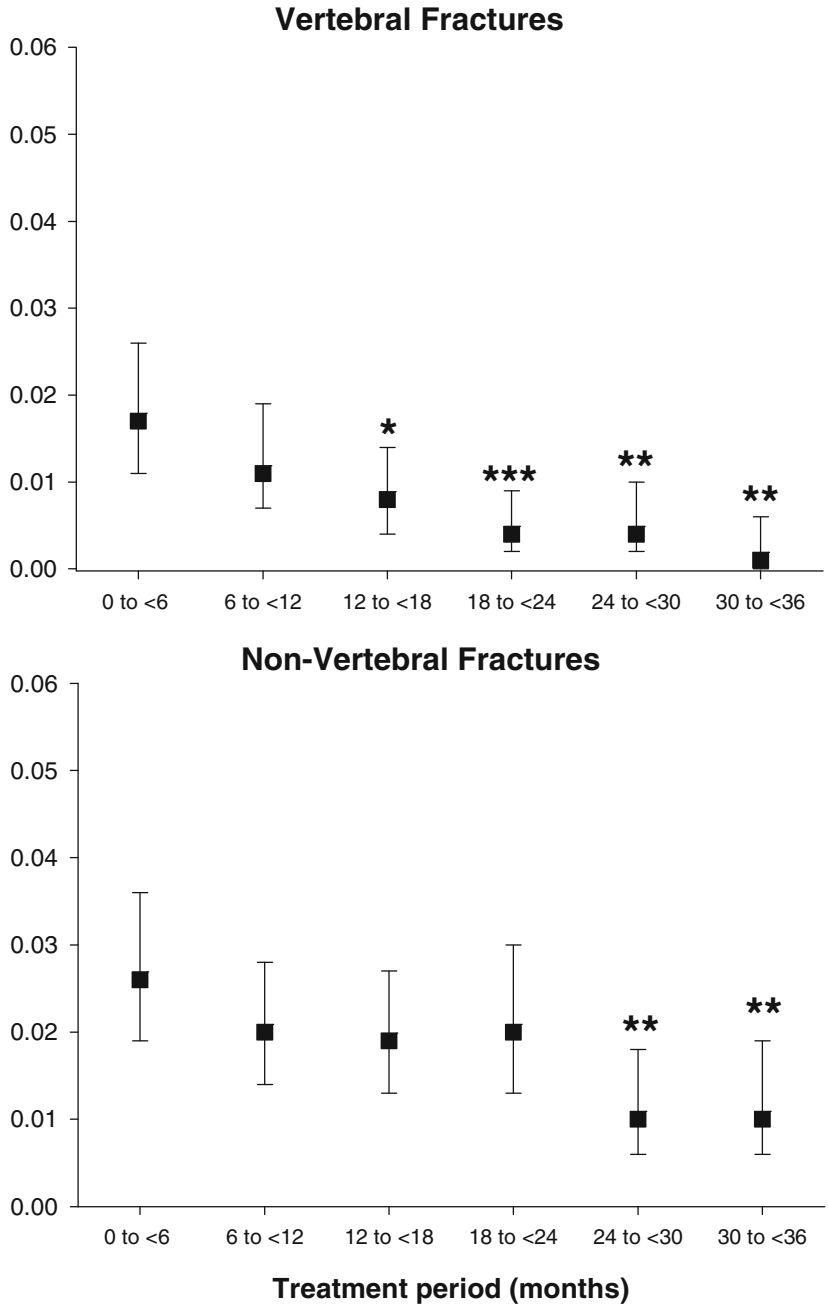

+ fracture in last 12 months. Models adjusted by age, prior bisphosphonate use and a history of fracture in the last 12 months before starting teriparatide. Main non-vertebral fractures includes forearm/wrist, hip, humerus, leg and ribs

the teriparatide treatment and were then maintained in the 18-month post-teriparatide period (Table 3).

Post-teriparatide cohort

This subgroup consisted of 909 patients who discontinued teriparatide treatment between baseline and 18 months, and returned for at least one post-treatment follow-up visit. The clinical characteristics of the post-teriparatide cohort were similar to the total study cohort (data not shown), although persistence with teriparatide was higher in the postteriparatide cohort than in the total study cohort (see Fig. S1).

In the post-teriparatide cohort, 50 patients $(5.5 \%)$ sustained a total of 58 fractures during the 18 months after teriparatide was discontinued. Of the 50 patients with a fracture, 43 sustained one fracture and seven sustained two or more fractures. Of the 58 fractures, $15(25.9 \%)$ were clinical 


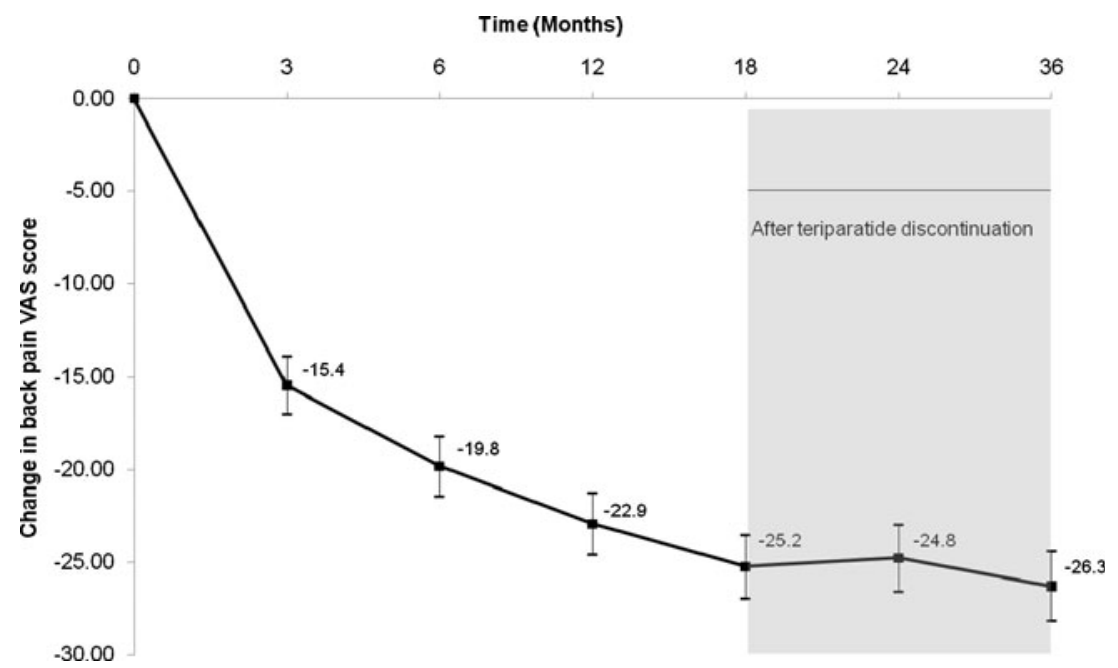

Fig. 3 Back pain VAS: adjusted mean change $(95 \% \mathrm{CI})$ from baseline during and after teriparatide treatment in total study cohort. Data presented is from MMRM analysis. Model included baseline back pain VAS score, number of previous fractures, fracture in 12 months before study entry, age, prior bisphosphonate duration, diagnosis of rheumatoid arthritis, and visit, where repeated measures were modelled with an

vertebral fractures and $43(74.1 \%)$ were non-vertebral fractures; $30(51.7 \%)$ were main non-vertebral fractures at the forearm/wrist $(n=7)$, hip $(n=6)$, humerus $(n=6)$, ribs $(n=$ $6)$, and leg $(n=5)$.

Data from the post-teriparatide cohort showed there was no evidence of further change in the odds of fracture during the 18 months after stopping teriparatide. The back pain results for the post-teriparatide cohort were similar to those for the total study cohort (data not shown).

\section{Safety}

A total of 351 adverse events were spontaneously reported by the physicians before discontinuation of teriparatide. Of these, 121 (34.5\%) were serious, $173(49.3 \%)$ were considered possibly related to study medication, and $22(6.3 \%)$ led to death. The most common adverse events reported were nausea (5.4\%) and headache $(4.3 \%)$, and the most common serious adverse events were death, transient ischaemic attack (4.1\% each), arrhythmia, myocardial infarction, cerebrovascular accident, dyspnoea and hypertension $(2.5 \%$ each).

After discontinuation of teriparatide, 31 adverse events were reported, all occurring either once or twice. Of these, 22 (71.0\%) were serious, five $(16.1 \%)$ were considered possibly related to study medication and ten $(32.3 \%)$ led to death.

\section{Discussion}

EFOS is the first observational study to report fracture rates together with back pain in postmenopausal women with unstructured correlation matrix. The unadjusted mean (SD) back pain VAS scores at 3, 6, 12, 18, 24, 36 months and end of study (LOCF) were 42.9 (25.0), 38.3 (25.4), 34.6 (25.6), 31.9 (25.5), 32.1 (26.7), 29.3 (26.3) and 33.5 (27.3) $\mathrm{mm}$, respectively. The unadjusted mean change from baseline to endpoint was -24.3 (SD 31.9)

severe osteoporosis in routine clinical practice both during teriparatide treatment for up to 18 months, and in the subsequent 18-month post-teriparatide period, when the majority of patients took other osteoporosis medications, mainly bisphosphonates. We observed beneficial effects on the adjusted odds of fracture during teriparatide treatment, with no evidence of further change in odds of fracture after teriparatide was discontinued. The adjusted odds of sustaining any clinical fracture or a vertebral fracture were significantly lower after 12 to $<18$ months of teriparatide treatment compared with the first 6 months. In addition, the adjusted odds of non-vertebral fracture were significantly lower after 24 to $<30$ months. Patients who had a fracture in the 12 months before baseline or who were previously treated with bisphosphonates were more likely to fracture during the study, probably reflecting the higher risk of fracture in these two patient subgroups [2]. The reduction in fractures was accompanied by a reduction in back pain during teriparatide treatment, with the changes in back pain being maintained for at least 18 months after teriparatide was discontinued.

Given the teriparatide reimbursement criteria in the participant countries, the patients taking part in EFOS had severe osteoporosis and a very high risk of fracture as indicated by their low BMD values, high number of previous fractures and presence of other risk factors at baseline. Moreover, many patients had chronic comorbidities $(32.5 \%)$ and/or took concomitant medications (63.8\%) that would have prevented them from taking part in controlled trials. Thus, the information provided by this observational study complements that provided by the 


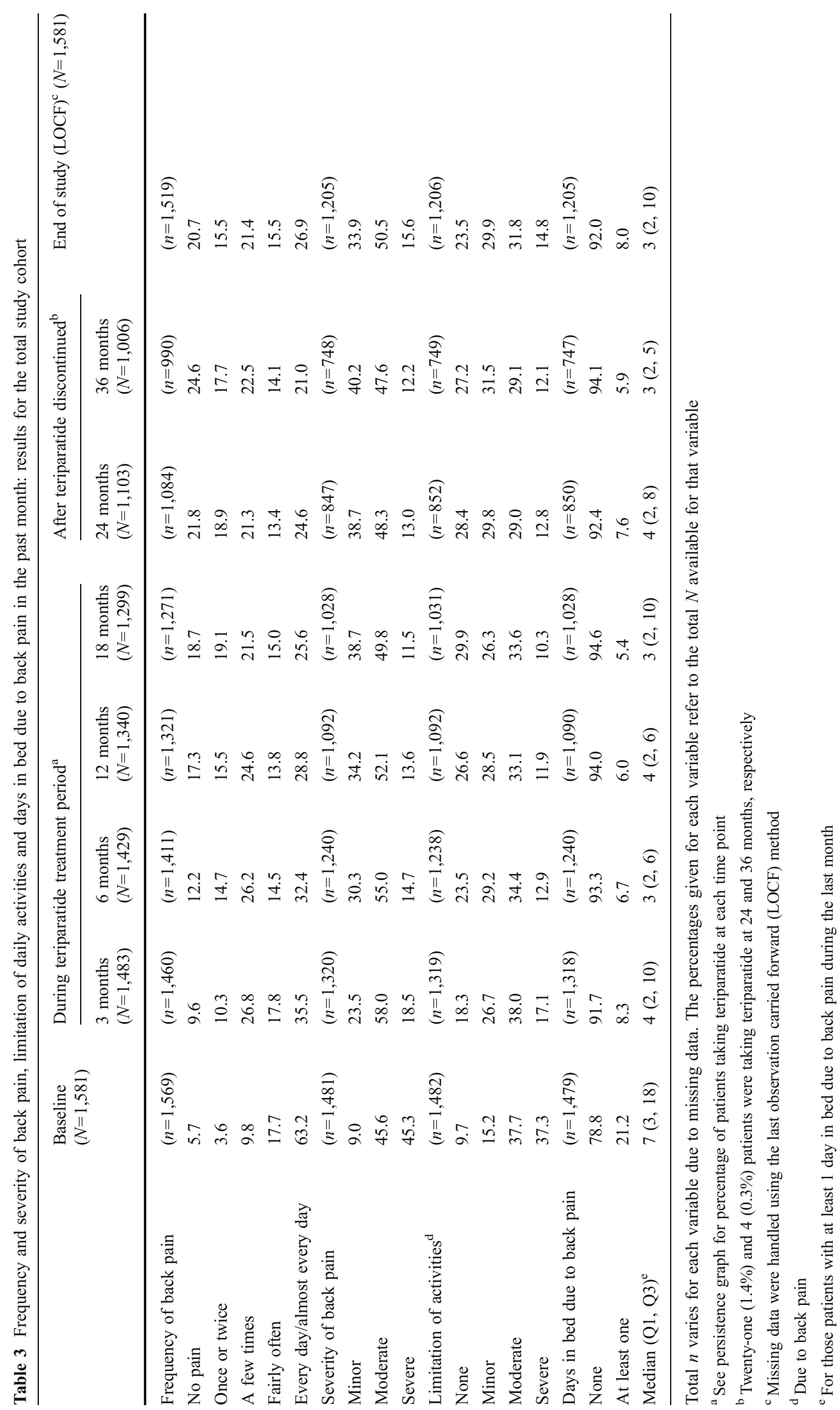


phase III pivotal trial [12], and recent randomised controlled studies in postmenopausal women with osteoporosis, which focused on BMD changes with different sequential therapies after teriparatide $[21,22]$ and may be useful for enhancing the management of patients suitable for treatment with teriparatide in routine care.

Moreover, this is one of the first studies to show the effectiveness of teriparatide in a large sample of osteoporosis patients receiving sequential therapies; the majority (73.4\%) of patients had been treated with bisphosphonates before study entry and $70.7 \%$ received osteoporosis medications during the 18-month post-teriparatide period.

A notable finding of our study is that a high percentage of patients completed their course of teriparatide therapy. Teriparatide was well tolerated, with few patients discontinuing treatment due to adverse events. Moreover, the adverse events reported were consistent with current prescription label information.

In the total study cohort, the odds of fracture were reduced by $39 \%$ at 12 to $<18$ months of treatment ( $p=$ 0.013 ) compared with the first 6 months of treatment; this decreased further to $74 \%$ at 30 to $<36$ months $(p<0.001)$. Our findings in previously treated patients of a reduced risk of fracture (both clinical vertebral and non-vertebral fractures) during teriparatide treatment that was unchanged after teriparatide was discontinued, are consistent with the results of the randomised placebo-controlled trial [12], and the observational follow-up to the trial $[23,24]$.

Our analyses of the fracture results also included data from patients after they had discontinued teriparatide, an uncommon approach in observational studies. This postteriparatide cohort allowed us to focus more specifically on what happened to patients after they discontinued teriparatide regardless of teriparatide duration.

It has been estimated that about three-quarters of patients with a clinical vertebral fracture experience chronic pain [4]. In the EFOS total study cohort, the mean back pain VAS score was high at baseline $(57.8 \mathrm{~mm})$, reflecting the severity of the disease. We observed a reduction in back pain during teriparatide treatment that was maintained after teriparatide was discontinued. The marked reduction in back pain during the first 3 months of teriparatide therapy is consistent with a meta-analysis of five randomised controlled trials, which found that the risk of new or worsening back pain was reduced by $34 \%$ after teriparatide treatment [25], and persisted during 30 months of post-treatment observational follow-up [26]. These earlier studies used data on back pain reported spontaneously by patients as an adverse event. In contrast, our study prospectively and comprehensively analysed back pain that was subjectively self-assessed by patients both during and after teriparatide treatment using a VAS and a specific pain questionnaire that evaluated back pain frequency and severity as well as activity limitations due to back pain. These back pain results must be interpreted with caution because recent randomised controlled trials have found similar reductions in pain during the first 3 months in both sham- and vertebroplasty-treated groups of patients with painful osteoporotic vertebral fractures [27, 28], although in one of the studies patients received an injection of local anaesthetic in the periosteum of the crushed vertebrae [28]. Moreover, back pain in patients who did not sustain a fracture during the follow-up period would reduce due to the natural course of the disease [2].

EFOS provided information on the use of different osteoporosis medications after the end of teriparatide treatment in normal clinical practice. The majority of patients $(70.7 \%)$ received antiresorptives (primarily bisphosphonates). Whether it was the long-term pharmacological effect of teriparatide on bone tissue, the contribution of this sequential medication, or both that affected the posttreatment risk of fracture is unclear, but the clinically relevant finding was that there was no evidence of deterioration in the odds of fracture or a rebound increase in back pain after teriparatide was discontinued. Antiresorptives such as alendronate, calcitonin and raloxifene have been reported to reduce back pain in postmenopausal women with osteoporosis [29-35]. It is unclear why we did not observe a further decline in back pain after teriparatide discontinuation when most patients were receiving antiresorptives. One possible explanation is that the patients had already reached a low level of back pain $(\sim 30 \mathrm{~mm})$.

Our study has several limitations. First, the results are specific to postmenopausal women with severe osteoporosis and may not be applicable to other types of patients receiving teriparatide. Second, we did not determine morphometric vertebral fractures as X-rays were only performed in symptomatic patients, so we may have underestimated the effectiveness in overall risk of vertebral fracture. Third, we did not gather data on the use of analgesics during the study. Fourth, the study was not designed to examine the maintenance of fracture efficacy after discontinuation of treatment, and the wide CIs show lack of power to determine fracture efficacy after teriparatide treatment was discontinued. Finally, the lack of a randomised control group prevents determination of the cause of the observed findings, especially subjective symptoms, such as back pain.

The strengths of the EFOS study include the prospective examination of clinical fractures in postmenopausal women with osteoporosis in real-life clinical practice both during teriparatide therapy and after teriparatide discontinuation. We also evaluated changes in pain over time using patientcompleted instruments, thereby gaining the patients' perspective. Our analyses adjusted for factors that may influence back pain, such as age, baseline level of pain, 
co-morbid rheumatoid arthritis, prior medication and fracture history.

In conclusion, this large observational study of postmenopausal women with severe osteoporosis and with comorbidities and co-medication showed that the incidence of clinical vertebral and non-vertebral fractures was reduced during 18 months of teriparatide treatment. We observed a $74 \%$ decrease in the adjusted odds of fracture in the 30 - to $<36$-month period compared with the first 6-month period $(p<0.001)$. The change in back pain occurred quickly, with the greatest change in the first 3 months of treatment, and was maintained during the 18 -month post-teriparatide period. Further research is needed to confirm these findings and to identify the best post-teriparatide treatment strategies for maintaining or even improving the beneficial effects of teriparatide therapy in the long term.

Acknowledgements This study was supported by a research grant from Lilly. The authors thank all physicians and patients participating in EFOS. The authors also thank Christine Jones, Lilly Germany, for the central study coordination. Deirdre Elmhirst helped in the preparation of the manuscript.

Conflicts of interest JB Walsh has been involved in studies in osteoporosis drugs produced by Merck Sharp and Dohme (MSD), Nycomed, Servier and Lilly, and has served on Advisory groups organised by MSD, Lilly, Proctor and Gamble, Servier and BristolMyers-Squibb. F Marin, A Barrett and C Barker are Lilly employees.

Open Access This article is distributed under the terms of the Creative Commons Attribution Noncommercial License which permits any noncommercial use, distribution, and reproduction in any medium, provided the original author(s) and source are credited.

\section{References}

1. Cockerill W, Lunt M, Silman AJ, Cooper C, Lips P, Bhalla AK, Cannata JB, Eastell R, Felsenberg D, Gennari C, Johnell O, Kanis JA, Kiss C, Masaryk P, Naves M, Poor G, Raspe H, Reid DM, Reeve J, Stepan J, Todd C, Woolf AD, O'Neill TW (2004) Healthrelated quality of life and radiographic vertebral fracture. Osteoporos Int 15:113-119

2. Cooper C, Jakob F, Chinn C, Martin-Mola E, Fardellone P, Adami S, Thalassinos NC, Melo-Gomes J, Torgerson D, Gibson A, Marin F (2008) Fracture incidence and changes in quality of life in women with an inadequate clinical outcome from osteoporosis therapy: the Observational Study of Severe Osteoporosis (OSSO). Osteoporos Int 19:493-501

3. Francis RM, Aspray TJ, Hide G, Sutcliffe AM, Wilkinson P (2008) Back pain in osteoporotic vertebral fractures. Osteoporos Int 19:895-903

4. Gold DT (1996) The clinical impact of vertebral fractures: quality of life in women with osteoporosis. Bone 18(Suppl 3):185-189

5. Johnell O, Kanis JA (2006) An estimate of the worldwide prevalence and disability associated with osteoporotic fractures. Osteoporos Int 17:1726-1733

6. Oleksik A, Lips P, Dawson A, Minshall ME, Shen W, Cooper C, Kanis J (2000) Health-related quality of life in postmenopausal women with low BMD with or without prevalent fractures. J Bone Miner Res 15:1384-1392

7. Salaffi F, Cimmino MA, Malavolta N, Carotti M, Di Matteo L, Scendoni P, Grassi W, Italian Multicentre Osteoporotic Fracture Study Group (2007) The burden of prevalent fractures on healthrelated quality of life in postmenopausal women with osteoporosis: the IMOF study. J Rheumatol 34:1551-1560

8. Silverman SL, Minshall ME, Shen W, Harper KD, Xie S (2001) The relationship of health-related quality of life to prevalent and incident vertebral fractures in postmenopausal women with osteoporosis: results from the Multiple Outcomes of Raloxifene Evaluation Study. Arthritis Rheum 44:2611-2619

9. Silverman SL, Piziak VK, Chen P, Misurski DA, Wagman RB (2005) Relationship of health related quality of life to prevalent and new or worsening back pain in postmenopausal women with osteoporosis. J Rheumatol 32:2405-2409

10. Cauley JA, Thompson DE, Ensrud KC, Scott JC, Black D (2000) Risk of mortality following clinical fractures. Osteoporos Int $11: 556-561$

11. Kanis JA, Burlet N, Cooper C, Delmas PD, Reginster J-Y, Borgstrom F, Rizzoli R, on behalf of the European Society for Clinical and Economic Aspects of Osteoporosis and Osteoarthritis (ESCEO) (2008) European guidance for the diagnosis and management of osteoporosis in postmenopausal women. Osteoporos Int 19:399-428

12. Neer RM, Arnaud CD, Zanchetta JR, Prince R, Gaich GA, Reginster JY, Hodsman AB, Eriksen EF, Ish-Shalom S, Genant HK, Wang O, Mitlak BH (2001) Effect of parathyroid hormone (1-34) on fractures and bone mineral density in postmenopausal women with osteoporosis. N Engl J Med 344:1434-1441

13. Dowd R, Recker RR, Heaney RP (2000) Study subjects and ordinary patients. Osteoporos Int 11:533-536

14. Silverman SL (2009) From randomized controlled trials to observational studies. Am J Med 122:114-120

15. Langdahl BL, Rajzbaum G, Jakob F, Karras D, Ljunggren O, Lems WF, Fahrleitner-Pammer A, Walsh JB, Barker C, Kutahov A, Marin F (2009) Reduction in fracture rate and back pain and increased quality of life in postmenopausal women treated with teriparatide: 18-month data from the European Forsteo Observational Study (EFOS). Calcif Tissue Int 85:484-493

16. Rajzbaum G, Jakob F, Karras D, Ljunggren O, Lems WF, Langdahl BL, Fahrleitner-Pammer A, Walsh JB, Gibson A, Tynan AJ, Marin F (2007) Characterization of patients in the European Forsteo Observational Study (EFOS): postmenopausal women entering teriparatide treatment in a community setting. Curr Med Res Opin 24:377-384

17. Ross PD (1997) Clinical consequences of vertebral fractures. Am J Med 103:30S-42S

18. Sriwatanakul K, Kelvie W, Lasagna L, Calimlim JF, Weis OF, Mehta G (1983) Studies with different types of visual analog scales for measurement of pain. Clin Pharmacol Ther 34:234-239

19. Laing YY, Zeger SL (1986) Longitudinal data analysis using generalised linear models. Biometrika 73:13-22

20. Hosmer DW Jr, Lemershow S (2000) Applied logistic regression, 2nd edn. Wiley, New York

21. Adami S, San Martin J, Muñoz-Torres M, Econs MJ, Xie L, Dalsky GP, McClung M, Felsenberg D, Brown JP, Brandi ML, Sipos A (2008) Effect of raloxifene after recombinant teriparatide [hPTH(1-34)] treatment in postmenopausal women with osteoporosis. Osteoporos Int 19:87-94

22. Eastell R, Nickelsen T, Marin F, Barker C, Hadji P, Farrerons J, Audran M, Boonen S, Brixen K, Melo Gomes J, ObermayerPietsch B, Avramidis A, Sigurdsson G, Gluer CC (2009) Sequential treatment of severe postmenopausal osteoporosis after teriparatide: final results of the randomized, controlled European Study of Forsteo (EUROFORS). J Bone Miner Res 24:726-736 
23. Lindsay R, Scheele WH, Neer R, Pohl G, Adami S, Mautalen C, Reginster J-Y, Stepan JJ, Myers SL, Mitlak BH (2004) Sustained vertebral fracture risk reduction after withdrawal of teriparatide in postmenopausal women with osteoporosis. Arch Intern Med 164:2024-2030

24. Prince R, Sipos A, Hossain A, Syversen U, Ish-Shalom S, Marcinowska E, Halse J, Lindsay R, Dalsky GP, Mitlak BH (2005) Sustained nonvertebral fragility fracture risk reduction after discontinuation of teriparatide treatment. J Bone Miner Res 20:1507-1513

25. Nevitt MC, Chen P, Dore RK, Reginster JY, Kiel DP, Zanchetta JR, Glass EV, Krege JH (2006) Reduced risk of back pain following teriparatide treatment: a meta-analysis. Osteoporos Int 17:273-280

26. Nevitt MC, Chen P, Kiel DP, Reginster JY, Dore RK, Zanchetta JR, Glass EV, Krege JH (2006) Reduction in the risk of developing back pain persists at least 30 months after discontinuation of teriparatide treatment: a meta-analysis. Osteoporos Int 17:1630-1637

27. Buchbinder R, Osborne RH, Ebeling PR, Wark JD, Mitchell P, Wriedt C, Graves S, Staples MP, Murphy B (2009) A randomized trial of vertebroplasty for painful osteoporotic vertebral fractures. N Engl J Med 361:557-568

28. Kallmes DF, Comstock BA, Heagerty PJ, Turner JA, Wilson DJ, Diamond TH, Edwards R, Gray LA, Stout L, Owen S, Hollingworth W, Ghdoke B, Annesley-Williams DJ, Ralston SH, Jarvik JG (2009) A randomized trial of vertebroplasty for osteoporotic spinal fractures. N Engl J Med 361:569-579

29. Nevitt MC, Thompson DE, Black DM, Rubin SR, Ensrud K, Yates AJ, Cummings SR, for the Fracture Intervention Trial Research
Group (2000) Effect of alendronate on limited-activity days and beddisability days caused by back pain in postmenopausal women with existing vertebral fractures. Arch Intern Med 160:77-85

30. Iwamoto J, Takeda T, Sato Y, Uzawa M (2004) Effects of alendronate on metacarpal and lumbar bone mineral density, bone resorption and chronic back pain in postmenopausal women with osteoporosis. Clin Rheumatol 23:383-389

31. Miller PD, Shergy WJ, Body J-J, Chen P, Rohe ME, Krege JH (2005) Long-term reduction of back pain risk in women with osteoporosis treated with teriparatide compared with alendronate. J Rheumatol 32:1556-1562

32. Knopp JA, Diner BM, Blitz M, Lyritis GP, Rowe BH (2005) Calcitonin for treating acute pain of osteoporotic vertebral compression fractures: a systematic review of randomized, controlled trials. Osteoporos Int 16:1281-1290

33. Papadokstakis G, Katonis P, Damilakis J, Hadjipavlou A (2005) Does raloxifene treatment influence back pain and disability among postmenopausal women with osteoporosis? Eur Spine J 14:977-981

34. Papadokostakis G, Damilakis J, Mantzouranis E, Katonis P, Hadjipavlou A (2006) The effectiveness of calcitonin on chronic back pain and daily activities in postmenopausal women with osteoporosis. Eur Spine J 15:356-362

35. Scharla S, Oertel H, Helsberg K, Kessler F, Langer F, Nickelsen T (2006) Skeletal pain in postmenopausal women with osteoporosis: prevalence and course during raloxifene treatment in a prospective observational study of 6 months duration. Curr Med Res Opin 22:2393-2402 